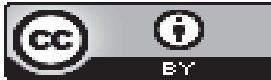

Online

\title{
Pretreatment with Magnesium Sulfate to Alleviate Pain on Propofol Injection: A Prospective Randomized Double Blind Study
}

\author{
MS Hossain 1, MM Rashid², MM Rashid ${ }^{3}$, MAR Babu4, A Sultana5, D Saha6, MI Hasan7
}

\begin{abstract}
Background and aim of study: Propofol is one of the most frequently used medications for inducing and maintaining anesthesia. However, propofol injection causes pain and discomfort in more than $70 \%$ of patients. This study was performed to determine the effect of magnesium sulfate on reducing pain at the onset of anesthesia induced by propofol injection. Materials and methods: A total of 80 healthy adult patients were selected in this study with either sex, scheduled for routine elective surgical procedure under general anesthesia. The patients enrolled were divided randomly into two groups of 40 patients each. Group I received $30 \mathrm{mg} / \mathrm{kg}$ of intravenous magnesium sulfate in $5 \mathrm{ml}$. Group II (placebo group) received $5 \mathrm{ml}$ of $0.9 \%$ intravenous normal saline 1 minute before propofol injection. The patients were asked to report their pain during injection of propofol. For all statistical tests, $p<0.05$ was taken to indicate a significant difference. Results: The incidence of pain experienced in magnesium sulfate group was $30 \%$ patients and in saline group was $60 \%$ patients, which is statistically significant $p<0.05$. The severity of POPI was also lower in magnesium sulfate group than the saline group $(p<0.05)$. The incidence of mild and moderate pain in groups I versus group II was $22.5 \%$ versus $37.5 \%$ and $7.5 \%$ versus $22.5 \%$ respectively $p<0.05$. There was no severe pain recorded in any groups. Conclusion: Magnesium sulfate can be used before induction of anesthesia to reduce pain on propofol injection.
\end{abstract}

Key words: Magnesium sulfate, general anesthesia, pain on propofol injection (POPI).

\section{Introduction:}

Propofol is one of the most popular intravenous anesthetic drugs. It has been used widely because of its numerous advantages including rapid induction and recovery and reducing postoperative nausea and vomiting. However, the incidence of pain following propofol injection is seen in almost $70 \%$ of patients, in the absence of other pretreatments. ${ }^{1-3}$ The mechanism by which

1. Dr. Muhammad Sazzad Hossain MBBS PhD FCPS (anes) Associate Professor and Head Department of AnesthesiologyNational Institute of ENT. Tejgaon, Dhaka.E mail: sazzadicu786@yahoo.com

2. Dr. Md. Mamunur Rashid DA Associate Professor (cc) Department of anesthesiology Gazi Medical College. Khulna.

3. Dr. Mohammad Mamunur Rashid DA Junior Consultant, Department of anesthesiology. NIENT.

4. Dr. Md. Anisur Rahman Babu DA Medical officer, Department of anesthesiology. NIENT.

5. Dr. Afsana Sultana DA Medical officer, Department of anesthesiology. NIENT.

6. Dr. Devashis Saha MBBS Research officer, Department of anesthesiology. NIENT.

7. Dr. Mohammad IftaKhiarul Hasan. MBBS. Medical officer. Anesthesiology Department of anesthesia, analgesia, palliative and Intensive care medicine Dhaka Medical College Hospital. 
propofol causes pain on injection is not fully understood. However, the activation of pain mediators, such as the kinin cascade system, has been suggested as a possible cause. ${ }^{3} \mathrm{~A}$ number of different interventions have been used to alleviate pain incidence and intensity during propofol injection, including administrating lignocaine, heating or cooling, diluting propofol, injecting it into a large vein, and using ondansetron, metoclopramide, clonidine, ketamine, narcotics, thiopentone and magnesium sulfate. It is not clear, which is the most effective. ${ }^{4-8}$

Magnesium sulfate is used to reduce propofol-induced pain. ${ }^{9}$ It is a natural calcium antagonist, which can be used as an adjuvant agent to reduce postoperative pain. ${ }^{10-12}$ Various studies have shown that magnesium sulfate can reduce the need for opiates, such as propofol, remifentanil, and vecuronium. ${ }^{13.14}$

This study was undertaken to evaluate the efficacy of $30 \mathrm{mg} / \mathrm{kg}$ of intravenous magnesium sulfate in comparison with placebo (normal saline) on incidence and severity of pain on propofol injection (POPI).

\section{Materials and methods}

This randomized double blinded controlled trial was performed in National Institute of ENT Dhaka, during July to September of 2018.Eighty patients with ASA class (American Society of Anesthesiologists) I-II aged 20-50 years, who were scheduled for elective ENT surgery under general anesthesia, were included and written informed consent was obtained separately before surgery. Patients with history of allergy to magnesium sulfate, neurological disorders, use of analgesic or sedative drugs in the 24 hours prior to surgery were excluded. All routine investigations were done for GA fitness.

The patients enrolled were divided randomly into two groups of 40 patients each. Group I was allocated to receive $30 \mathrm{mg} / \mathrm{kg}$ of intravenous magnesium sulfate. Group II (placebo group) was allocated to receive $5 \mathrm{ml}$ of $0.9 \%$ intravenous normal saline. Study drugs were prepared in the same shape of $5 \mathrm{ml}$ syringe, by an anesthesiologist who was not involved in the study.

On arrival to the operation room, standard monitoring was applied to all patients including pulse oximeter, electrocardiogram and noninvasive arterial blood pressure.A 20-gauge intravenous cannula was placed on the dorsum of non-dominant hand of the patient and Ringer's solution was started. Patients received no premedication. While the venous drainage was occluded by placing an air-filled tourniquet (pressure inflated to 70 $\mathrm{mm} \mathrm{Hg}$ ) on the upper arm by an assistant; a blinded anesthesiologist injected prepared study drug or saline according to the allocation. The occlusion was released after one minute. First one-fourth of induction dose (2 $\mathrm{mg} / \mathrm{kg}$ ) of propofol was injected slowly over 10 seconds. The pain intensity was measured based on McCririck and Hunter scale. ${ }^{15}$ After the assessment of pain, induction of anesthesia was completed with the remaining dose of propofol then tracheal intubation was facilitated with the injection of succinylcholine. Anesthesia was maintained with injection of fentanyl, vecuronium, oxygen, nitrous oxide $(66 \%)$ and halothane. When surgery was completed general anesthesia was reversed as usual.

Grading of pain: As per McCririck and Hunter scale $^{15}$

$0=$ No pain

1=Mild pain (pain reported only in response to questioning without any behavioral signs)

$2=$ Moderate pain (pain reported in response to questioning and accompanied by a behavioral sign or pain reported spontaneously without questioning).

$3=$ Severe pain (strong vocal response or response accompanied by facial grimacing, arm withdrawal or tears).

Statistical analysis: For comparison of quantitative variables between the two groups, the unpaired t-test and for qualitative variables 
the Chi-squared test was used. The statistically significant level was $\mathrm{P}<0.05$.

\section{Results}

There was no significant demographic difference between the groups (Table 1).

Basal MAP and HR were comparable in both groups. There was no significant difference of MAP and HR between magnesium sulfate and saline groups during pre-intubation or three minutes post-intubation period $(p>0.05)$ (Table II).

The incidence of pain experienced in magnesium sulfate group (group I) was $30 \%$ patients and in group II (saline group) was 60\% patients, which is statistically significant $p<0.05$ (Table III). The severity of POPI was also lower in magnesium sulfate group than the saline group $(p<0.05)$ (Table III). The incidence of mild and moderate pain in groups I versus group II was $22.5 \%$ versus $37.5 \%$ and $7.5 \%$ versus $22.5 \%$ respectively $p<0.05$. There was no severe pain recorded in any groups.

\section{Discussion}

Propofol, an excellent IV anesthetic agent belonging to the phenol group, can irritate the skin, the mucous membrane and the venous intima. The mechanism of pain is attributed to the activation of the kinin-kallikrein system that releases bradykinin, causing vasodilatation and hyper-permeability, thereby increasing contact between the aqueous phase propofol and the free nerve endings. Several authors have studied the mechanisms and methods of reducing propofol injection pain.

The results obtained from the present study showed, the overall incidence and severity of pain were significantly less in magnesium group compared to placebo group. The incidence of pain experienced in magnesium sulfate groups $30 \%$ patients and insaline group is in $60 \%$ patients. The severity of POPI is also lower in magnesium sulfate group than the saline group.

Khoshfefrat et al.16 had a study on prevention of propofol injection induced pain using

Table 1: Comparison of demographic data between the two groups

\begin{tabular}{|l|c|c|c|}
\hline \multicolumn{1}{|c|}{ Parameters } & $\begin{array}{c}\text { Group I (Magnesium } \\
\text { sulfate group) } \mathrm{n}=40 .\end{array}$ & $\begin{array}{c}\text { Group II (Saline group) } \\
\mathrm{n}=40 .\end{array}$ & $\mathrm{p}$ value \\
\hline Age in years (mean \pm SD) & $36.23 \pm 8.34$ & $38.12 \pm 9.54$ & $\mathrm{p}>0.05$ \\
\hline Weight in kg (mean \pm SD) & $65.28 \pm 8.47$ & $64.54 \pm 8.62$ & $\mathrm{p}>0.05$ \\
\hline Sex (male/female) & $27 / 13$ & $28 / 12$ & $\mathrm{p}>0.05$ \\
\hline ASA Physical status I/II & $37 / 3$ & $36 / 4$ & $\mathrm{p}>0.05$ \\
\hline
\end{tabular}

Table 2: Changes of mean arterial pressure and heart rate between two groups

\begin{tabular}{|l|c|c|c|}
\hline $\begin{array}{l}\text { Hemodynamic } \\
\text { parameter }\end{array}$ & $\begin{array}{c}\text { Basal } \\
\text { Group I / Group II }\end{array}$ & $\begin{array}{c}\text { Pre intubation } \\
\text { Group I / Group II }\end{array}$ & $\begin{array}{c}\text { Post intubation } \\
\text { Group I / Group II }\end{array}$ \\
\hline $\begin{array}{l}\text { Mean arterial pressure } \\
\text { (MAP) mm Hg }\end{array}$ & $94 / 98$ & $91 / 93$ & $102 / 105$ \\
\hline Heart rate per minute & $81 / 84$ & $73 / 76$ & $92 / 90$ \\
\hline
\end{tabular}

Table 3: Incidence and severity of pain following propofol injection between two groups

\begin{tabular}{|l|c|c|c|}
\hline $\begin{array}{l}\text { Characteristics of } \\
\text { pain }\end{array}$ & $\begin{array}{c}\text { Group I (Magnesium Sulfate } \\
\text { group) } \mathrm{n}=40 . \text { Number and \% }\end{array}$ & $\begin{array}{c}\text { Group II (Saline group) } \\
\mathrm{n}=40 . \text { Number and } \%\end{array}$ & $\mathrm{p}$ value \\
\hline No pain & $28(70 \%)$ & $16(40 \%)$ & $\mathrm{p}<0.05$ \\
\hline Pain & $12(30 \%)$ & $24(60 \%)$ & $\mathrm{p}<0.05$ \\
\hline Mild pain & $9(22.5 \%)$ & $15(37.5 \%)$ & $\mathrm{p}<0.05$ \\
\hline Moderate pain & $3(7.5 \%)$ & $9(22.5 \%)$ & $\mathrm{p}<0.05$ \\
\hline Severe pain & 0 & 0 & - \\
\hline
\end{tabular}


magnesium, ketamine and lignocaine. They observed $20 \%$ patients experienced pain during propofol injection in magnesium pretreatment group.

A study done by Safavi et al.17 on attenuation of pain induced by injection of propofol by pretreatment of magnesium and found 34\% patients experienced pain during propofol injection.

The study on prevention of pain on propofol injection using magnesium sulfate by Akbari et al. 8 observed $36 \%$ patients experienced pain during injection of propofol.

Another study done by Memis et al.9 in their report showed that magnesium sulfate can reduce the pain due to propofol injection. In their study, the patients were divided into normal saline and magnesium groups and their observation showed, also $36 \%$ of patients reported pain in the magnesium group.

In another study, titled "Paracetamol, Ondansetron, Granisetron, Magnesium Sulfate and Lidocaine and Reduced Propofol injection pain" by Alipour et al.18 showed pain observed with Paracetamol in $72 \%$ patients, Ondansetron61\%, granesetron30\% Magnesium $48 \%$ and Lidocaine $30 \%$ patients.

Galgon et al.19 showed in his study, on prevention of Propofol injection pain using magnesium sulfate and Lidocaine and they found, $57 \%$ patients complained pain in magnesium sulfate group and $29 \%$ patients complained pain in lidocaine group.

Li M et al. 20 has a Study titled "Effects and safety of Magnesium sulfate on Propofolinduced injection pain, a meta-analysis of randomized controlled trials". They also concluded that pretreatment with Magnesium sulfate intravenously before injecting Propofol significantly reduced Propofol injection induced pain.

Present study shows, complains of pain in $30 \%$ patients in magnesium group which is lowerthan those studies by Alipouret al.18 and Galgon et al.19 but nearly similar to those studies of Safavi et al.17, Akbari et al. 8 and Memis et al.9

\section{Conclusion}

Pretreatment with a dose of $30 \mathrm{mg} / \mathrm{kg}$ magnesium sulfate intravenously administered one minute before propofol injection can reduce the incidence and severity of pain on propofol injection without significant adverse effects.

\section{References}

1. Zahedi, H, Maleki, A. Ondansetron Pretreatment Reduces Pain on Injection of Propofol. ActaMedicalranica. 2012; 50(4):239-43.

2. Tan $\mathrm{CH}$, Onsiong MK. Pain on injection of propofol. Anaesthesia 1988; 53:468-76.

3. Cheong MA, Kim KS, Choi WJ. Ephedrine reduces the pain from propofol injection. AnesthAnalg. 2002; 95(5):1293-96.

4. Macario $A$, Weinger $M$, Truong $P$, Lee $M$. Which clinical anesthesia outcomes are both common and important to avoid? The perspective of a panel of expert anesthesiologists. AnesthAnalg 1999; 88(5):1085-91.

5. Ambesh SP, Dubey PK, Sinha PK. Ondansetron pretreatment to alleviate pain on propofol injection: a randomized, controlled, double-blinded study. Anesth Analg.1999; 89(1):197-9.

6. Ishiyama $\mathrm{T}$, Kashimoto $\mathrm{S}$, Oguchi $\mathrm{T}$, Furuya A, Fukushima H, Kumazawa T. Clonidine-ephedrine combination reduces pain on injection of propofol and blunts hemodynamic stress responses during the induction sequence. J ClinAnesth. 2006; 18(3):211-5.

7. Saadawy I, Ertok E, Boker A. Painless injection of propofol: pretreatment with ketamine vs thiopental, meperidine, and lidocaine. Middle East J Anesthesiol. 2007; 19(3):631-44.

8. Akbari H, Nasiri E, Nikkhah A, Ardehali 
$\mathrm{SH}$. Analgesic Effects of Ketamine, Magnesium Sulfate, and Sodium-Thiopental on Propofol Injection Pain: A Single-Blind Randomized Clinical Trial. Tanaffos 2018; 17(1): 22-8.

9. Memi $\square$ D, Turan A, Karamanlio $\square$ lu B, Süt $\mathrm{N}$, Pamukçu Z. The use of magnesium sulfate to prevent pain on injection of propofol. AnesthAnalg 2002;95(3):606-8,

10. LevauxCh, Bonhomme V, Dewandre PY, Brichant JF, Hans P. Effect of intraoperative magnesium sulphate on pain relief and patient comfort after major lumbar orthopaedic surgery. Anaesthesia 2003;58(2):131-5.

11. Bhatia A, Kashyap L, Pawar DK, Trikha A. Effect of intraoperative magnesium infusion on perioperative analgesia in open cholecystectomy. J ClinAnesth 2004;16(4):262-5.

12. Seyhan TO, Tugrul M, Sungur MO, Kayacan S, Telci L, Pembeci K, Akpir K. Effects of three different dose regimens of magnesium on propofol requirements, haemodynamic variables and postoperative pain relief in gynaecological surgery. $\mathrm{Br} \mathrm{J}$ Anaesth 2006;96(2):247-52.

13. Choi JC, Yoon KB, Um DJ, Kim C, Kim JS, Lee SG. Intravenous magnesium sulfate administration reduces propofolinfusionrequirements during maintenance of propofol-N2O anesthesia: part I: comparing propofol requirements according to hemodynamic responses: part II: comparing bispectral index in control and magnesium groups. Anesthesiology 2002; 97(5):1137-41.
14. Telci L, Esen F, Akcora D, Erden T, Canbolat AT, Akpir K. Evaluation of effects of magnesium sulphate in reducing intraoperative anaesthetic requirements. $\mathrm{Br} \mathrm{J}$ Anaesth 2002;89(4):594-8.

15. McCrirrick $A$, Hunter S. Pain on injection of propofol: the effect of injectated temperature. Anaesthesia 1990; 45: 443-4.

16. Khoshfefrat M, Beirami F, Panah FS, Keykha A. A comparison of premedication injections of magnesium sulfate, ketamine and lidocaine on severity of pain induced by intravenous injection of propofol. Archives of Anesthesiology and Critical Care 2017; 3(4): 382-84.

17. Safavi M, Honarmand A. Magnesium sulfate pretreatment to alleviate pain on propofol injection: a comparison with ketamine or lidocaine. Journal of Mazandaran University of Medical Sciences. 2007; 17(60):30-8.

18. Alipour M, Tabari $M$ and Alipour $M$. Paracetamol, Ondansetron,Granisetron, Magnesium Sulfate and Lidocaine and Reduced Propofol Injection Pain. Iran Red Cresent J 2014;16:e16086.

19. GalgonRE, Strube P, HeierJ Groth J, Wang $S$ and Schroeder KM. Magnesium Sulfate with Lidocaine for preventing Propofol injection pain: a randomized, double-blind, placebo controlled trial. J Anesth 2014;206-11.

20. Li M, Zhao X, Zhang L, Niu X,GuoT,Yang $B$ Liu Z. Int J ClinExp Med 2015;8(5):6813-6821. 